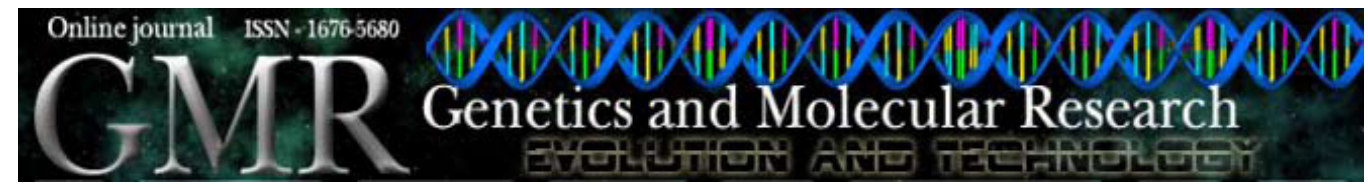

\title{
Evaluation of genetic diversity in jackfruit (Artocarpus heterophyllus Lam.) based on amplified fragment length polymorphism markers
}

\author{
S. Shyamalamma ${ }^{1}$, S.B.C. Chandra ${ }^{2}$, M. Hegde ${ }^{1}$ and P. Naryanswamy ${ }^{1}$ \\ ${ }^{1}$ Plant Molecular Biology Laboratory, Division of Horticulture, \\ University of Agricultural Sciences, GKVK, Bangalore, India \\ ${ }^{2}$ Department of Biological, Chemical and Physical Sciences, \\ Roosevelt University, Chicago, IL, USA \\ Corresponding author: S.B.C. Chandra \\ E-mail: schandra@roosevelt.edu
}

Genet. Mol. Res. 7 (3): 645-656 (2008)

Received May 15, 2008

Accepted June 23, 2008

Published July 22, 2008

\begin{abstract}
Artocarpus heterophyllus Lam., commonly called jackfruit, is a medium-sized evergreen tree that bears high yields of the largest known edible fruit. Yet, it has been little explored commercially due to wide variation in fruit quality. The genetic diversity and genetic relatedness of 50 jackfruit accessions were studied using amplified fragment length polymorphism markers. Of 16 primer pairs evaluated, eight were selected for screening of genotypes based on the number and quality of polymorphic fragments produced. These primer combinations produced 5976 bands, 1267 (22\%) of which were polymorphic. Among the jackfruit accessions, the similarity coefficient ranged from 0.137 to 0.978 ; the accessions also shared a large number of monomorphic fragments (78\%). Cluster analysis and principal component analysis grouped all jackfruit genotypes into three major clusters. Cluster I included the genotypes grown in a jackfruit region of Karnataka, called Tamaka, with very dry conditions; cluster II contained the genotypes collected from
\end{abstract}


locations having medium to heavy rainfall in Karnataka; cluster III grouped the genotypes in distant locations with different environmental conditions. Strong coincidence of these amplified fragment length polymorphism-based groupings with geographical localities as well as morphological characters was observed. We found moderate genetic diversity in these jackfruit accessions. This information should be useful for tree breeding programs, as part of our effort to popularize jackfruit as a commercial crop.

Key words: Jackfruit; Genetic diversity; Markers; Polymorphism; Amplified fragment length polymorphism

\section{INTRODUCTION}

Jackfruit (Artocarpus heterophyllus Lam.) belongs to the family Moraceae, indigenous to the rainforests of the Western Ghats of India (Rowe-Dutton, 1985). It is cultivated widely at low elevations throughout India, in many parts of Southeast Asia (Rahman et al., 1999), in the evergreen forest zone of West Africa (Burkill, 1997), and in northern Australia as well (Azad et al., 2007). Jackfruit is a medium-sized evergreen tree, typically reaching 8-25 $\mathrm{m}$ in height, producing heavier yields than any other tree species, and bears the largest known edible fruit (up to $35 \mathrm{~kg}$ ). The jackfruit tree has several uses. Flakes of ripe fruits are high in nutritive value; every $100 \mathrm{~g}$ of ripe flakes contains $287-323 \mathrm{mg}$ potassium, 30.0-73.2 $\mathrm{mg}$ calcium and 11-19 g carbohydrates (Samaddar, 1985). In Bangladesh, it is commonly referred to as "poor man's food" (Rahman et al., 1995) as it is cheap and plentiful during the season. The nutritious seeds are boiled or roasted and eaten like chestnuts, added to flour for baking, or cooked in dishes. The tree is also known for its durable timber, which ages to an orange or reddish brown color, with anti-termite properties. The leaves and fruit waste provide valuable fodder for cattle, pigs and goats. Jackfruit wood chips yield a dye, which is used to give the famous orange-red color to the robes of Buddhist priests (Craig and Harley, 2006). In addition, many parts of the plant, including the bark, roots, leaves and fruits have medicinal properties (Hakim et al., 2005; Arung et al., 2006).

Despite numerous advantages, the popularity of jackfruit as a commercial crop is very poor owing to wide variations in fruit quality, the long seed dormancy and the widespread belief that excessive consumption of jackfruit flakes leads to certain digestive ailments (Samaddar, 1985). Several studies have reported diversity in jackfruit, but they were based mainly on morphological characteristics (Hossain, 1996; Saha et al., 1996, Jagadeesh et al., 2007). Although at least 30 strains have been described in the Indian subcontinent and 30 more types in Malaysia (Singh, 1986; Vinning and Moody, 1997), only two types are recognized on the basis of fruit characteristics (Odoemelam, 2005); one has fruits with small, fibrous, soft and spongy flakes with very sweet carpels, while the other variety is crunchy, though not as sweet, with crisp carpels. This latter is considered to be of high quality, called "Koozha chakka" or "Koozha pazham" in South India. There are no well-defined varieties in specific localities; local varieties have different names based on their variability in yield, fruit shape, flake color, total sugars, and so on. Cultivar identification and estimation of genetic diversity using morphological data are limited, as they are environmentally influenced, and there are few distinctive 
characters (Cavagnaro et al., 2006). Markers aided by polymorphisms in proteins and DNA structures have reduced the disadvantages of morphological markers to some extent (Sensoy et al., 2007), because they are unaffected by environmental factors (Dhanaraj et al., 2002).

Jackfruit is a tetraploid; its somatic chromosome number is $(4 n) 56$. Therefore, the basic chromosome number is 14 (Darlington and Wylie, 1956). Only one study until now by Schnell et al. (2001) looked at the genetic diversity of 26 accessions from different parts of the world, using amplified fragment length polymorphism (AFLP) markers, and provided an actual picture of diversity and genetic relatedness in jackfruit. This study included only two accessions from India, and they scored a small number of markers (187), of which 92 (49.2\%) were found to be polymorphic. The most recent study by Azad et al. (2007) looked at isozyme variation in jackfruit in Bangladesh. A total of 50 accessions were evaluated for four enzyme systems, and isozyme patterns were determined on the basis of number and position of bands. They discovered that morphological traits such as weight, length, girth of the fruits and percentage of pulp correlated poorly with environmental factors, suggesting that these characters are more likely genetically controlled. However, isozyme markers are also known to be affected by both environment and post-translation modification, and their practical use is limited (Akashi et al., 2002).

To date, no one has made an attempt to estimate the genetic diversity of different jackfruit cultivars in India. A comprehensive understanding of genetic diversity and molecular characterization of jackfruit cultivars is needed for formulating appropriate sampling and management strategies. A detailed analysis of a large number of genetic markers will provide us with useful gene conservation strategies and help in popularizing this species as a commercial crop. Among many available DNA-based markers, AFLP markers are more reliable, yield a large number of markers per reaction, are cost-effective and have wide genome coverage (Prashanth et al., 2002; Hansen et al., 1999). AFLP markers have been successfully used, in the last decade, as a satisfactory alternative as well as compliment to morphological data in a variety of plant and tree species (Basha et al., 2007; Mahmud et al., 2007; Sreekumar et al., 2007). The purpose of the present study was to estimate the level of genetic diversity and to assess genetic relationships among 50 jackfruit accessions, collected from different parts of south India, using AFLP markers.

\section{MATERIAL AND METHODS}

\section{Plant material and DNA extraction}

In the present study, 30 jackfruit accessions were obtained from the germplasm collection, from the southern part of India, maintained at the University of Agricultural Sciences (GKVK), Bangalore, India. The remaining 20 accessions representing the following four populations were collected from different locations in south India: Tamaka (17), Hebbal (1), Malleshwaram (1) and Hosur (1) (Table 1). The genotypes were named after the locality from where they were collected. The morphological characteristics of the each accession were recorded based on the descriptors provided by the International Plant Genetic Resource Institute (IPGRI, 2000). Approximately $5 \mathrm{~g}$ of recently matured leaves (15-20 days old) was collected, washed using distilled water, wiped with $70 \%(\mathrm{v} / \mathrm{v})$ ethanol and then air dried, of which $1 \mathrm{~g}$ was weighed out and stored in sealed plastic bags at $-80^{\circ} \mathrm{C}$. 


\begin{tabular}{|c|c|c|c|}
\hline Sl. No. & Cultivar & Place of collection & Accession \# \\
\hline 1 & $\mathrm{~T} 1$ & Hort. Farm, Tamaka, Kolar & TK-1 \\
\hline 2 & $\mathrm{~T} 2$ & Hort. Farm, Tamaka, Kolar & TK-2 \\
\hline 3 & $\mathrm{~T} 3$ & Hort. Farm, Tamaka, Kolar & TK-3 \\
\hline 4 & $\mathrm{~T} 4$ & Hort. Farm, Tamaka, Kolar & TK-4 \\
\hline 5 & T5 & Hort. Farm, Tamaka, Kolar & TK-5 \\
\hline 6 & T6 & Hort. Farm, Tamaka, Kolar & TK-6 \\
\hline 7 & $\mathrm{~T} 7$ & Hort. Farm, Tamaka, Kolar & TK-7 \\
\hline 8 & $\mathrm{~T} 8$ & Hort. Farm, Tamaka, Kolar & TK-8 \\
\hline 9 & T9 & Hort. Farm, Tamaka, Kolar & TK-9 \\
\hline 10 & $\mathrm{~T} 10$ & Hort. Farm, Tamaka, Kolar & TK-10 \\
\hline 11 & $\mathrm{~T} 11$ & Hort. Farm, Tamaka, Kolar & TK-11 \\
\hline 12 & $\mathrm{~T} 12$ & Hort. Farm, Tamaka, Kolar & TK-12 \\
\hline 13 & $\mathrm{~T} 13$ & Hort. Farm, Tamaka, Kolar & TK-13 \\
\hline 14 & $\mathrm{~T} 14$ & Hort. Farm, Tamaka, Kolar & TK-14 \\
\hline 15 & $\mathrm{~T} 15$ & Hort. Farm, Tamaka, Kolar & TK-15 \\
\hline 16 & $\mathrm{~T} 16$ & Hort. Farm, Tamaka, Kolar & TK-16 \\
\hline 17 & $\mathrm{~T} 17$ & Hort. Farm, Tamaka, Kolar & TK-17 \\
\hline 18 & Tanevarika & Dabaspet, Tumkur & HRS-J-10 \\
\hline 19 & Farm Office & Senior FS Office, GKVK & HRS-J-8 \\
\hline 20 & Tubagere & Tubagare, Doddaballapur & HRS-J-4 \\
\hline 21 & YLD/JND & MRS, Hebbal & HRS-J-7 \\
\hline 22 & Malleshwaram & Malleshwaram, Bangalore & MBR-1 \\
\hline 23 & GKVK 1 & HRS, Scion Bank & HRS-J-6 \\
\hline 24 & SSB-15 (B) & UAS B-15 Quarters, Hebbal & HRS-J-3 \\
\hline 25 & SSB-15 (F) & UAS B-15 Quarters, Hebbal & HRS-J-2 \\
\hline 26 & Gumless & HRS, Scion Bank & HRS-J-11 \\
\hline 27 & HMT (M) & HRS, Scion Bank & HRS-J-5 \\
\hline 28 & Kerala & Fruit crop nursery & HRS-J-12 \\
\hline 29 & HMT (ICAR) & Fruit crop nursery & HRS-J-13 \\
\hline 30 & Mandya Madhura & HRS, Scion Bank & HRS-J-9 \\
\hline 31 & FSO $(\mathrm{M})$ & Farm Office, GKVK & FS-M \\
\hline 32 & FSO-1 & Farm Office, GKVK & FS-1 \\
\hline 33 & FSO-2 & Farm Office, GKVK & FS-2 \\
\hline 34 & FSO-3 & Farm Office, GKVK & FS-3 \\
\hline 35 & FSO-4 & Farm Office, GKVK & FS-4 \\
\hline 36 & FSO-5 & Farm Office, GKVK & FS-5 \\
\hline 37 & Mottavarika & HRS, Scion Bank & HRS-J-1 \\
\hline 38 & FSO-6 & Farm Office, GKVK & FS-6 \\
\hline 39 & M-0 & HRS, Scion Bank & HRS-J-1-1 \\
\hline 40 & V Nursery & Vegetable nursery, HRS & HRS-J-14 \\
\hline 41 & O Nursery & Ornamental nursery, HRS & HRS-J-15 \\
\hline 42 & FSO-7 & Farm Office, GKVK & FS-7 \\
\hline 43 & SF-1 & Sunflower Scheme, GKVK & SF-1 \\
\hline 44 & SF-2 & Sunflower Scheme, GKVK & SF-2 \\
\hline 45 & TC Jack & Tissue Culture Jack, HRS & HRS-J-16 \\
\hline 46 & Chandra Halasu & HRS, Scion Bank & HRS-J-17 \\
\hline 47 & HMT(SB) & HRS, Scion Bank & HRS-J-18 \\
\hline 48 & M-1 & HRS, Scion bank & HRS-J-19 \\
\hline 49 & NTI & NTI layout, Hebbal & NTI-1 \\
\hline 50 & Simon & Hosur, TamilNadu & SHT-1 \\
\hline
\end{tabular}

Extraction of DNA was performed with a modified cetyl trimethyl ammonium bromide (CTAB) method (Dellaporta et al., 1983) with a few modifications. One gram of leaf sample was 
powdered in liquid nitrogen and mixed with $10 \mathrm{~mL}$ extraction buffer containing $100 \mathrm{mM}$ Tris$\mathrm{HCl}, \mathrm{pH}$ 8.0, $20 \mathrm{mM}$ EDTA, $1.4 \mathrm{M} \mathrm{NaCl}, 3 \%$ (w/v) CTAB, 2\% polyvinyl pyrrolidone and 1\% $\beta$-mercaptoethanol. The contents were then mixed slowly and were incubated in a water bath at $65^{\circ} \mathrm{C}$ for $1 \mathrm{~h}$ with intermittent shaking. After incubation, the contents were brought to room temperature and $5 \mathrm{~mL}$ chloroform:isoamyl alcohol mixture (24:1) was added to the tube. The mixture was agitated thoroughly and centrifuged at $8000 \mathrm{rpm}$ for $20 \mathrm{~min}$ at $4^{\circ} \mathrm{C}$. This procedure was continued until a clear supernatant was obtained. After the final spin, the supernatant was taken to a separate tube and an equal volume of ice-cold isopropanol was added to precipitate the DNA overnight at $4^{\circ} \mathrm{C}$. On the next day, the sample was centrifuged at $5000 \mathrm{rpm}$ and the DNA pellet washed with 2-3 drops 70\% alcohol, air-dried and dissolved in TE buffer. To remove RNA, each sample was incubated with $5 \mu \mathrm{L}$ ribonuclease $(10 \mathrm{mg} / \mathrm{mL})$ and incubated at room temperature overnight. To remove proteins, the samples were mixed with an equal volume of phenol:chloroform:isoamyl alcohol (25:24:1) and centrifuged at 14,000 rpm for $2 \mathrm{~min}$, and the top aqueous DNA layer was taken and DNA precipitated by adding two volumes of ice-cold ethanol. The precipitation was improved by keeping at $-20^{\circ} \mathrm{C}$ overnight, and then spun at $9000 \mathrm{rpm}$ for $20 \mathrm{~min}$ to pellet the DNA. The pellet was washed with $70 \%$ ethanol and dried in a vacuum drier for half an hour. The pellet was dissolved in $300 \mu \mathrm{L}$ TE buffer, to which $1 / 10$ volume $3 \mathrm{M}$ sodium acetate was added and left overnight. The supernatant was collected after $24 \mathrm{~h}$ by spinning at $9000 \mathrm{rpm}$ for $20 \mathrm{~min}$. The DNA was quantified using Hoefer's Dyna Quant and verified by electrophoresis on $0.8 \%$ agarose gels.

\section{AFLP procedure and polymerase chain reaction amplification}

The original AFLP protocol outlined by Vos et al. (1995) was followed with silverstaining technique for the development of gels. The restriction enzymes EcoRI and MseI, ligase enzyme, adaptors and primers were purchased from Life Science Technologies, USA. The polymerase chain reaction (PCR) was performed with an MJ Research PTC-100 Thermocycler (Bio-Rad Laboratories, Bangalore, India). In all the jackfruit genotypes, double digestion was carried out using the EcoRI and MseI enzymes at 10 and $4 \mathrm{U} / \mu \mathrm{L}$ concentrations, respectively. Five hundred nanograms of genomic DNA was used for restriction-ligation of EcoRI and MseI adapters. Pre-selective amplification was performed on 1:1 diluted restriction digestion reaction products with pre-selective primers, which had adaptor sequence and additional nucleotide extension at 3' ends. The list of primer pair combinations used is presented in Table 2. PCR amplification was conducted in two stages. The pre-selective amplification was performed with an amplification profile of $94^{\circ} \mathrm{C}$ for $30 \mathrm{~s}$, annealing at $56^{\circ} \mathrm{C}$ for $1 \mathrm{~min}$, extension at $72^{\circ} \mathrm{C}$ for $1 \mathrm{~min}$, repeated for 20 cycles, and then at $10^{\circ} \mathrm{C}$ for $30 \mathrm{~min}$. After this, the products were diluted 1:1 ratio and selective amplification was performed with a cycling profile of $94^{\circ} \mathrm{C}$ for $30 \mathrm{~s}, 65^{\circ} \mathrm{C}$ for $30 \mathrm{~s}$ reducing by $0.7 / \mathrm{cycle}$ to $56^{\circ} \mathrm{C}, 72^{\circ} \mathrm{C}$ for $1 \mathrm{~min}$ for $11 \mathrm{cycles}$, followed by $94^{\circ} \mathrm{C}$ for $30 \mathrm{~s}$, $56^{\circ} \mathrm{C}$ for $30 \mathrm{~s}$, and $72^{\circ} \mathrm{C}$ for $1 \mathrm{~min}$ for 24 cycles followed by $10^{\circ} \mathrm{C}$ for $30 \mathrm{~min}$. The primers used for selective amplification ended with three nucleotide extensions at 3' ends (Table 2). PCR were carried out separately for each primer pair and the products were denatured immediately by adding $8 \mu \mathrm{L}$ of stop/loading dye to each sample. The samples were heated to $94^{\circ} \mathrm{C}$ for 5 min to cause denaturation and then cooled to $10^{\circ} \mathrm{C}$ for $5 \mathrm{~min}$. Finally, the product was stored at $-20^{\circ} \mathrm{C}$. Electrophoresis of the samples was carried out on polyacrylamide gels, by loading $3 \mu \mathrm{L}$ of each DNA sample. Electrophoresis was carried out at $1600 \mathrm{~V}$ for $1.5 \mathrm{~h}$ until the dark blue dye ran off. The gels were then separated and developed by silver-staining technique. 


\begin{tabular}{|c|c|c|}
\hline \multirow[t]{2}{*}{ Sl. No. } & \multicolumn{2}{|c|}{ Primer combinations } \\
\hline & Pre-amplification & Selective amplification \\
\hline 1 & $E c o \mathrm{RI}+\mathrm{A} / \mathrm{MseI}+\mathrm{C}$ & EcoRI + ACT / MseI - CTT \\
\hline 2 & $E c o R I+T / M s e I+G$ & $E c o R I+\mathrm{TAG} / M s e \mathrm{I}-\mathrm{GAT}$ \\
\hline 3 & $E c o \mathrm{RI}+\mathrm{G} / M s e \mathrm{I}+\mathrm{T}$ & $\mathrm{Eco \textrm {RI }}+\mathrm{GAC} / \mathrm{Mse} \mathrm{I}-\mathrm{TCA}$ \\
\hline 4 & $E c o R I+C / M s e I+A$ & $E c o \mathrm{RI}+\mathrm{CGT} / \mathrm{MseI}-\mathrm{AAT}$ \\
\hline 5 & $E c o \mathrm{RI}+\mathrm{A} / M s e \mathrm{I}+\mathrm{C}$ & $E c o \mathrm{RI}+\mathrm{AGG} / \mathrm{MseI}-\mathrm{CAA}$ \\
\hline 6 & $E c o \mathrm{RI}+\mathrm{A} / M s e \mathrm{I}+\mathrm{C}$ & EcoRI + AGT / MseI - CAG \\
\hline 7 & $E c o \mathrm{RI}+\mathrm{A} / M s e \mathrm{I}+\mathrm{C}$ & $E c o R I+\mathrm{ACA} / \mathrm{MseI}-\mathrm{CTG}$ \\
\hline 8 & $E c o R I+C / M s e I+A$ & EcoRI + CTA / MseI - AGG \\
\hline 9 & $E c o \mathrm{RI}+\mathrm{G} / M s e \mathrm{I}+\mathrm{T}$ & $E c o \mathrm{RI}+\mathrm{GTA} / \mathrm{MseI}$ - TAA \\
\hline 10 & $E c o R I+\mathrm{G} / M s e \mathrm{I}+\mathrm{T}$ & $E c o \mathrm{RI}+\mathrm{GAC} / \mathrm{MseI}-\mathrm{TCG}$ \\
\hline
\end{tabular}

\section{Data analysis}

The AFLP products that showed clear polymorphism in the samples were visually scored as a binary matrix for presence (1) and absence (0) of bands. A pairwise similarity matrix between genotypes was estimated according to the Nei and Li (1979) similarity coefficient, $S_{i j}=2 a /(2 a+b+c)$ : where $S_{i j}$ is the similarity between two individuals $i$ and $j$, ' $a$ ' is the number of bands shared by both individuals, ' $b$ ' is the number of bands present in $i$ and absent in $j$, and ' $c$ ' is the number of bands present in $j$ and absent in $i$. The similarity matrix was then analyzed using Ward's clustering method using a minimum variance algorithm (Ward Jr., 1963). A dendrogram was constructed with the TREE program using STATISTICA version 8.0 (SoftStat, Inc.). Principal component analysis (PCA) of the correlation matrix was used to further investigate relationships between individuals.

\section{RESULTS AND DISCUSSION}

The use of eight selective primer combinations on 50 samples of Artocarpus heterophyllus resulted in a total of 5796 markers, of which 1267 were polymorphic. The markers obtained were consistent, unambiguous and repeatable in most cases. The number of polymorphic markers per primer combination ranged from 65 to 241 with the average number of polymorphic bands being 158 (Table 3). The highest number of polymorphic bands (241) was generated with E-ACT/M-CTT primer combination, followed by E-ACA/M-CTG (235) and E-AGT/M-CAG (208). The average percentage of polymorphism shown by eight primers was $21.85 \%$, whereas, it was highest $(32.8 \%)$ in the primer combination E-CGT/M-AAT followed by E-ACA/M-CTG (28.6\%). The level of polymorphism observed in our study was lower than that of Schnell et al. (2001), reported in earlier AFLP studies on jackfruit. Their results showed $49 \%$ polymorphism based on 12 primer combinations. The high level of polymorphism that they saw in their study could be explained due to the fact that the accessions evaluated included 26 cultivars from 8 different countries comprising three different continents. In addition, a total of only 187 markers were scored in the study, and this might have contributed to a higher percentage of polymorphism than what is normally observed in intraspecific cultivars. In our study, the level of polymorphism is a little higher than what is reported for many intraspecific 
AFLP studies: 10\% among celery cultivars grown in California (Li and Quiros, 2000) and $11.8 \%$ in wheat cultivars adapted to the Pacific Northwest region (Barrett and Kidwell, 1998). $\mathrm{Li}$ and Quiros (2000) attributed the low level of polymorphism in celery to a large genome size with extensive areas of repetitive DNA.

Table 3. Selective primers and level of polymorphism among Artocarpus heterophyllus cultivars from amplified
fragment length polymorphism analysis.
\begin{tabular}{rcrcrc}
\hline S1. No. & $\begin{array}{c}\text { Primer } \\
\text { combination }\end{array}$ & $\begin{array}{r}\text { Total } \\
\text { bands }\end{array}$ & $\begin{array}{c}\text { Monomorphic } \\
\text { bands }\end{array}$ & $\begin{array}{c}\text { Polymorphic } \\
\text { bands }\end{array}$ & $\begin{array}{c}\text { Percentage of } \\
\text { polymorphism }\end{array}$ \\
\hline 1 & E-ACT/M-CTT & 1025 & 784 & 241 & $23.52 \%$ \\
2 & E-TAG/M-GAT & 479 & 414 & 65 & $13.56 \%$ \\
3 & E-AGG/M-CAA & 847 & 722 & 125 & $14.75 \%$ \\
4 & E-AGT/M-CAG & 1091 & 883 & 208 & $19.06 \%$ \\
5 & E-CGT/M-AAT & 506 & 340 & 115 & $32.80 \%$ \\
6 & E-CTA/M-AGG & 500 & 385 & 112 & $23.00 \%$ \\
7 & E-GAC/M-TCA & 527 & 415 & 235 & $21.25 \%$ \\
8 & E-ACA/M-CTG & 821 & 4529 & 1267 & $28.62 \%$ \\
& Total & 5796 & 586 & $21.85 \%$ \\
\hline
\end{tabular}

Genetic similarities based on Nei and Li similarity coefficients revealed a moderate level of diversity within the accessions evaluated (Table 4). The average genetic similarity among 50 jackfruit accessions ranged from a low of 0.137 to a high of 0.978 with an average similarity among this group of accessions of 0.563 . In contrast to an earlier study by Schnell et al. (2001), a moderate genetic diversity exists within our collection of cultivars. The genetic similarity coefficients for 26 jackfruit accessions in their study ranged from a low of 0.567 to a high of 0.95 with a high average of similarity of 0.743 . Their marker analysis showed limited genetic diversity within 26 jackfruit accessions collected from eight different countries. In the present study, FSO-4 cultivar was found to be most genetically similar to Tamaka-17 (0.978), suggesting similar selection pressure in these two locations. Tamaka-1 and Tamaka-2 cultivars were found to be the least genetically similar (0.137), despite coming from similar geographical localities. Moreover, 17 Tamaka cultivars (from 1 to 17 ) that were collected from Kolar had a lower average similarity coefficient value of 0.512 , further asserting the existence of genetic diversity among these cultivars, despite growing in the same geographical region. Interestingly, genotypes such as Tanevarika, Tamaka-17, Tamaka-10, Mottavarika, TC Jack, M-1 and Simon exhibited much higher similarity coefficient values ranging from a low of 0.5571 to a high of 0.9023 . Although each of these genotypes represented different geographical locations in the southern part of India, the majority of them had morphologically similar attributes such as broad, thick, pubescent leaves and elongated fruits with sharp vines and dark green rind. These results are in agreement with the most recent study by Azad et al. (2007) in jackfruit, suggesting that these fruit characteristics correlated poorly with environmental factors and were therefore likely genetically controlled. A moderate amount of genetic diversity does exist among jackfruit accessions. Taken as a whole, the results clearly show that jackfruit germplasm with medium diversity could play an important role in the preservation of genetic diversity and enhancement of jackfruit cultivars. 


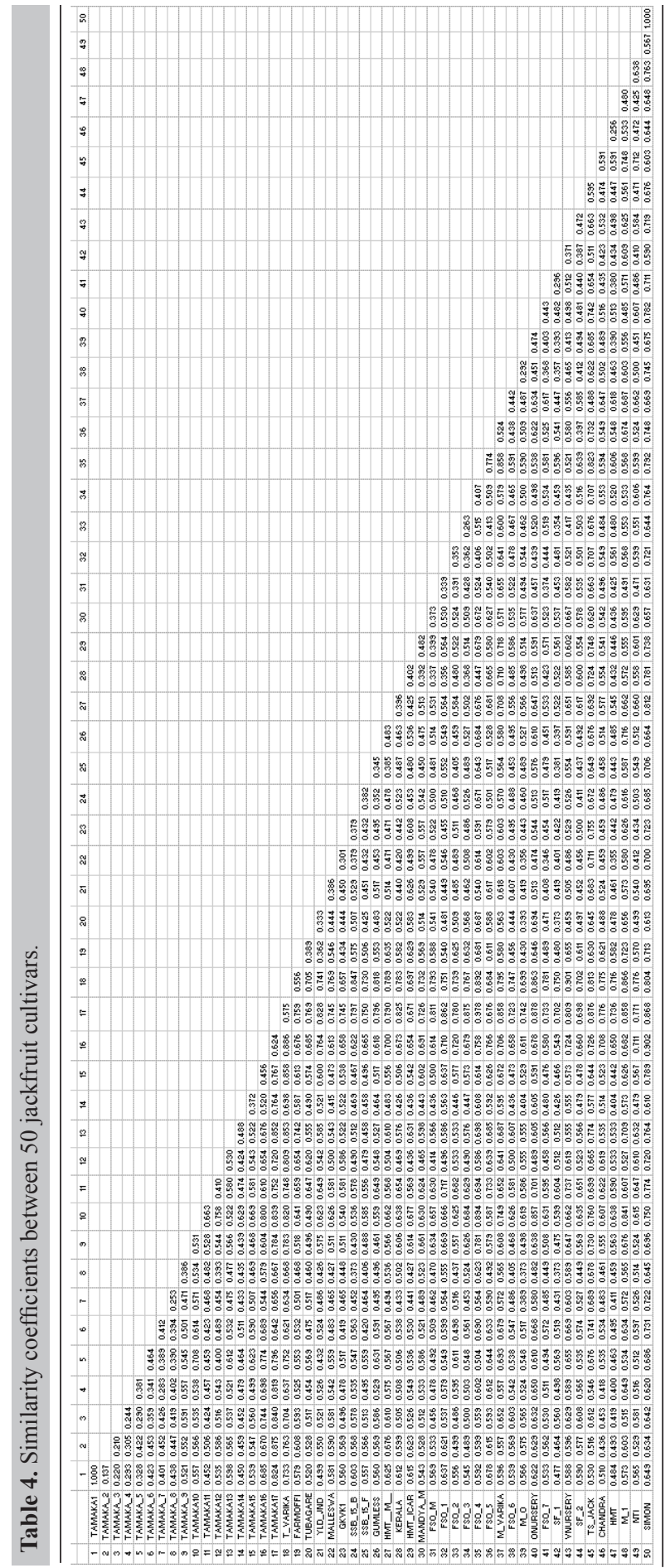


The genetic relationships of jackfruit cultivars were further evaluated by Ward's cluster analysis, on AFLP data set, using a minimum variance algorithm. It resulted in three main branches with a linkage distance of 3 to 7.5 units with Tamaka-1 and Simon at the extreme ends of the dendrogram (Figure 1). Cluster I consisted of 9 accessions (Tamaka-1-9) grouped at a linkage distance of 3.4 to 5.5 units, collected from the same location, Kolar in Karnataka State. All these genotypes had fairly similar morphological attributes. Tamaka-1 and Tamaka-2, the closest genotypes, were placed at a linkage distance of 3.4 units, and then were linked to Tamaka-3 at 4.5 units. All these Tamaka genotypes were seedling progenies growing in relatively dry conditions, with little variations in fruit size, shape and color of flakes, thus indicating common origin from surrounding places. Cluster II consisted of 21 genotypes (Farm Office to HMT) grouped at a linkage distance of 5.0 to 6.0 units. Although the genotypes in this cluster represented accessions from distant locations, these geographical locations had similar environmental conditions such as medium to heavy rainfall. Most of these genotypes had similar attributes as well. Chandrahalasu and HMT had a linkage distance of 5.0 units, the closest in this group, and both had an oblong fruit shape with green rind. The two most distant genotypes in this group, Tubagere and HMT, had a linkage distance of close to 6 units, as these two were fairly further away from each other in terms of geographical location, therefore under different environmental conditions. Cluster III consisted of 20 genotypes (HMTICAR to Simon), which were clustered at a fairly narrow genetic linkage of distance of 6.10 to 7.00 units. There were four sub-clusters within this group having different genotypes in each sub-cluster. Sub-cluster-I had three types viz., HMT-ICAR, SF-2 and FSO-5; all the three genotypes had oblong fruits, each weighing more than $15 \mathrm{~kg}$. Sub-cluster-II had Tamaka-12, -14, -15 and -16 types, and these genotypes exhibited oval fruit shape with medium-sized fruits weighing 5-8 kg. Sub-clusterIII contained O Nursery, NTI, HMT (M), M-1, Tamaka-11 and -13. Sub-cluster-IV had Mottavarika, TC Jack, Tamaka-10, Tamaka-17, Tanevarika and Simon types; most of these genotypes were collected from regions with heavy rainfall and always bore elongated fruits.

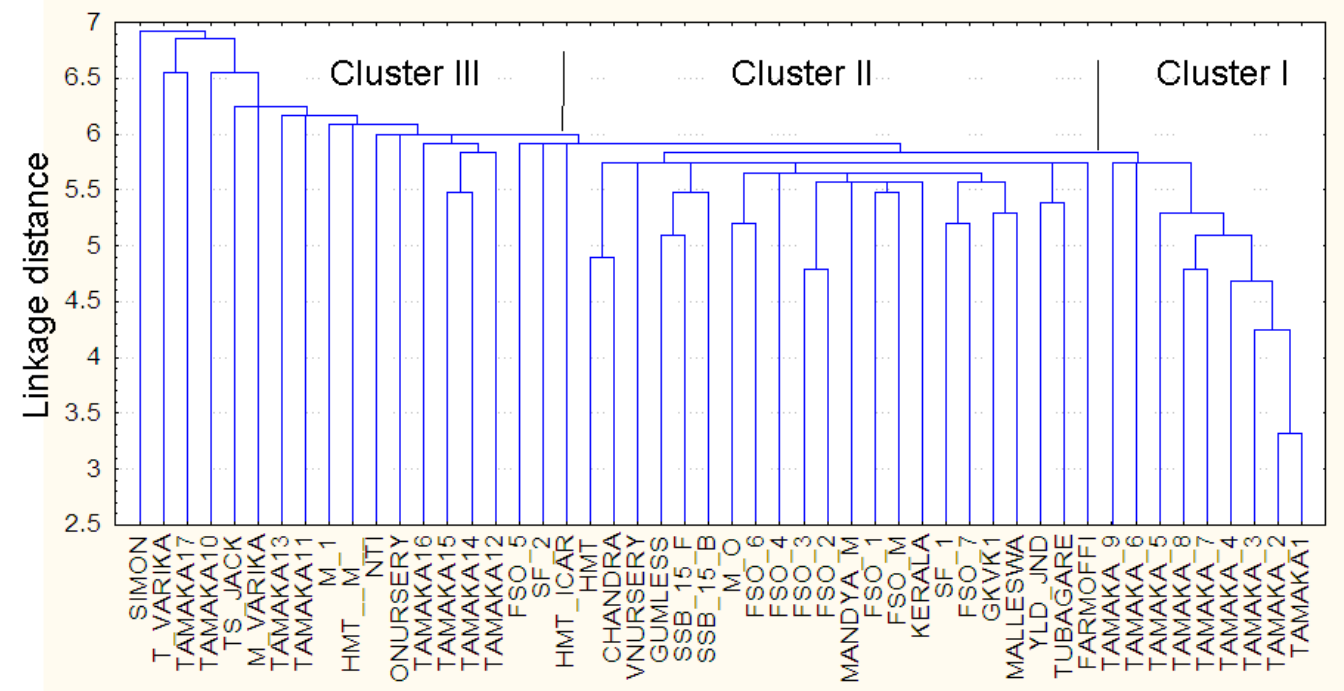

Figure 1. UPGMA-based dendrogram generated by amplified fragment length polymorphism molecular data. 
The principal component analysis based on AFLP data separated populations into three distinct groups (Figure 2) that were comparable with those of branches produced by cluster analysis. The first axis accounted for $24.2 \%$ of the total variation, whereas the second explained a further $18.1 \%$ of the total variation. PCA carried out using AFLP markers further asserted the existence of genetic diversity in the jackfruit cultivars. It showed that the genotypes such as Tamaka-17 and Tanevarika were divergent and far away in the cluster indicating their distant relations with other genotypes. The rest of the genotypes were dispersed on the PCA plot which was a reflection of moderate genetic diversity in these accessions. Some of the genotypes appeared to be overlapping in the PCA picture, depicting their close genetic relations with each other. The results obtained from PCA were in agreement with the dendrogram generated by Ward's cluster analysis.

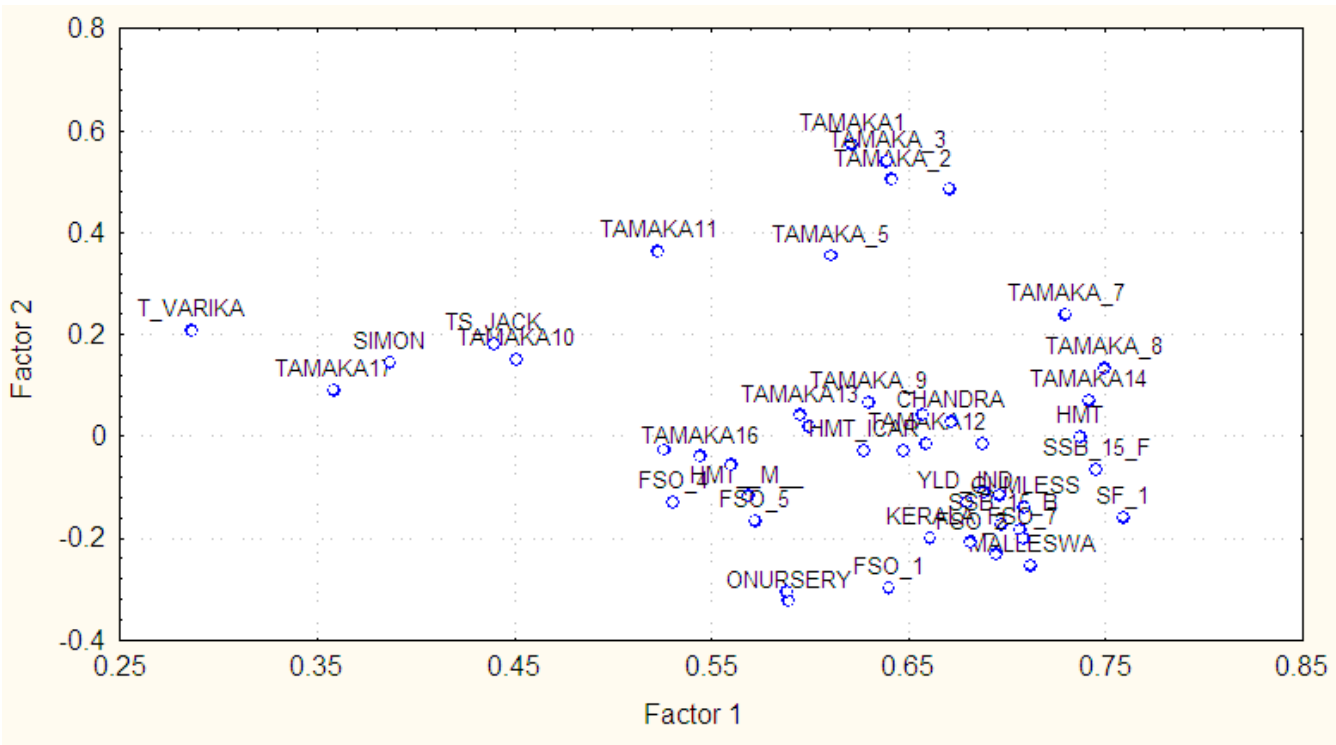

Figure 2. Two-dimensional principal component analysis based on amplified fragment length polymorphism molecular data.

In conclusion, the evidence from AFLP analysis indicates the existence of a moderate degree of genetic diversity in jackfruit cultivars. Even though this study showed close relationships among a few genotypes studied, there were still no duplicates. Although we found a good correlation between genetic and geographical data, future studies involving a large number of morphological traits with molecular markers should have important implications for germplasm management. The development of jackfruit cultivars with superior properties such as fruit quality, short gestation period, disease resistance and human health benefits will be very important for promoting commercial production. AFLP makers have proved to be effective for characterizing the genetic basis of $A$. heterophyllus for assessing genetic diversity and relatedness between accessions. The result of this study is of critical importance for jackfruit breeding programs as well as informed and efficient management of germplasm collections. 


\section{REFERENCES}

Akashi Y, Fukuda N, Wako T, Masuda M, et al. (2002). Genetic variation and phylogenetic relationships in East and South Asian melons, Cucumis melo L., based on the analysis of five isozymes. Euphytica 125: 385-396.

Arung ET, Shimizu K and Kondo R (2006). Inhibitory effect of artocarpanone from Artocarpus heterophyllus on melanin biosynthesis. Biol. Pharm. Bull. 29: 1966-1969.

Azad AK, Jones JG and Haq N (2007). Assessing morphological and isozyme variation of jackfruit (Artocarpus heterophyllus Lam.) in Bangladesh. Agroforestry Syst. 71: 109-125.

Barrett BA and Kidwell KK (1998). AFLP-based genetic diversity assessment among wheat cultivars from the Pacific Northwest. Crop Sci. 38: 1261-1271.

Basha AI, Padulosi S, Chabane K, Hadj-Hassan A, et al. (2007). Genetic diversity of Syrian pistachio (Pistacia vera L.) varieties evaluated by AFLP markers. Gen. Res. Crop Evol. 54: 1807-1816.

Burkill HM (1997). The Useful Plants of West Tropical Africa. 2nd edn. Royal Botanic Gardens, Kew.

Cavagnaro PF, Cavagnaro JB, Lemes JL, Masuelli RW, et al. (2006). Genetic diversity among varieties of the native forage grass Trichloris crinita based on AFLP markers, morphological characters, and quantitative agronomic traits. Genome 49: 906-918.

Craig RE and Harley IM (2006). Artocarpus heterophyllus (jackfruit). Species Profiles for Pacific Island Agroforestry. www.traditionaltree.org. Accessed February 14, 2007.

Darlington CD and Wylie AP (1956). Chromosome atlas of flowering plants. Allen and Unwin, London.

Dellaporta SL, Wood J and Hicks JB (1983). A plant DNA minipreparation: version II. Plant Mol. Biol. Rep. 1: 19-21.

Dhanaraj AL, Rao EVVB, Swamy KRM, Bhat MG, et al. (2002). Using RAPDs to assess the diversity in Indian cashew (Anacardium occidentale L.) germplasm. J. Hort. Sci. Biotech. 77: 41-47.

Hakim EH, Juliawaty LD, Syah YM and Achmad SA (2005). Molecular diversity of Artocarpus champeden (Moraceae): a species endemic to Indonesia. Mol. Divers. 9: 149-158.

Hansen M, Kraft T, Christiansson M and Nilsson NO (1999). Evaluation of AFLP in Beta sp. Theor. Appl. Genet. 98: 845-852.

Hossain AKMA (1996). Status report on genetic resources of jackfruit in Bangladesh. IPGRI Regional Office, Singapore.

IPGRI (2000). Descriptors for jackfruit (Artocarpus heterophyllus Lam.). IPGRI, Rome. ISBN 92-90423-450-3.

Jagadeesh SL, Reddy BS, Basavaraj N, Swamy GSK, et al. (2007). Inter tree variability for fruit quality in jackfruit selections of Western Ghats of India. Sci. Hort. 112: 382-387.

Li G and Quiros CF (2000). Use of amplified fragment length polymorphism markers for celery cultivar identification. Hort. Sci. 35: 726-728.

Mahmud MA, Kitaura H, Fukuda M and Yamada A (2007). AFLP analysis for examining genetic differences in cultivated strains and their single-spore isolates and for confirming successful crosses in Agaricus blazei. Mycoscience 48: 297-304.

Nei M and Li WH (1979). Mathematical model for studying genetic variation in terms of restriction endonucleases. Proc. Natl. Acad. Sci. U. S. A. 76: 5269-5273.

Odoemelam SA (2005). Functional properties of raw and heat processed jackfruit (Artocarpus heterophyllus) flour. Pak. J. Nutr. 4: 366-370.

Prashanth SR, Parani M, Mohanty BP, Talame V, et al. (2002). Genetic diversity in cultivars and landraces of Oryza sativa subsp. indica as revealed by AFLP markers. Genome 45: 451-459.

Rahman AKMM, Huq E, Mian AJ and Chesson A (1995). Microscopic and chemical changes occurring during the ripening of two forms of jackfruit (Artocarpus heterophyllus L). Food Chem. 52: 405-410.

Rahman AKMM, Nahar N, Mian AJ and Mosihuzzaman M (1999). Variation of carbohydrate composition of two forms of fruit from jack tree (Artocarpus heterophyllus L) with maturity and climatic conditions. Food Chem. 65: 91-97.

Rowe-Dutton P (1985). Artocarpus heterophyllus - jackfruit. In: The propagation of tropical fruit trees (Garner RJ and Chaudhri SA, eds.). FAO, Rome (Italy); Commonwealth Bureau of Horticulture and Plantation Crops, Maidstone, 269-290.

Saha MC, Saha MG, Rahman MA, Nazrul MI, et al. (1996). Variability in jackfruit. A paper presented at the Internal Research Review Workshop. Horticulture Research Centre, BARI, Gazipur, Bangladesh, 1-4.

Sammadar HM (1985). Jackfruit. In: Fruits of India: Tropical and Subtropical (Bose TK and Mitra SK, eds.). Naya Prokash, Calcutta, 638-649.

Schnell RJ, Olano CT, Campbell RJ and Brown JS (2001). AFLP analysis of genetic diversity within a jackfruit germplasm collection. Sci. Hort. 91: 261-274. 
Sensoy S, Büyükalaca S and Abak K (2007). Evaluation of genetic diversity in Turkish melons (Cucumis melo L.) based on phenotypic characters and RAPD markers. Genet. Res. Crop Evol. 54: 1351-1365.

Singh A (1986). Fruit Physiology and Production. Kalyani Publishers, New Delhi-Ludhiana, 349-367.

Sreekumar VB, Binoy AM and George ST (2007). Genetic and morphological variation in breadfruit (Artocarpus altilis (Park.) Fosberg) in the Western Ghats of India using AFLP markers. Gen. Res. Crop Evol. 54: 1659-1665.

Vinning G and Moody T (1997). A Market Compendium of Tropical Fruits. RIRDC Research Report No. 97/74. Rural Industries Res. and Development Corporation, Barten.

Vos P, Hogers R, Bleeker M, Reijans M, et al. (1995). AFLP: a new technique for DNA fingerprinting. Nucleic Acids Res. 23: 4407-4414.

Ward JH Jr (1963). Hierarchical grouping to optimize an objective function. J. Am. Stat. Assoc. 58: 236-244. 